Review began $08 / 23 / 2021$ Review ended 09/12/2021 Published 09/21/2021

(c) Copyright 2021

Parker et al. This is an open access article distributed under the terms of the Creative Commons Attribution License CC-BY 4.0 ., which permits unrestricted use, distribution, and reproduction in any medium, provided the original author and source are credited.

\section{Factors Predictive of Publication Among Medical Students Participating in School-Sponsored Research Programs}

\author{
Sean M. Parker ${ }^{1}$, Linda C. Vona-Davis ${ }^{2}$, Malcolm D. Mattes ${ }^{3}$
}

1. Department of Medical Education, West Virginia University, Morgantown, USA 2. Office of Research and Graduate Education, West Virginia University, Morgantown, USA 3. Department of Radiation Oncology, Rutgers Cancer Institute of New Jersey, New Brunswick, USA

Corresponding author: Malcolm D. Mattes, malcolm.mattes@gmail.com

\begin{abstract}
Introduction: Publishing research is an important component of medical students' career development and becoming a more competitive residency applicant. Many medical schools offer structured programs to enable students to participate in research during their preclinical and clinical years, but the majority of studentmentor partnerships do not culminate in publication across a variety of institutions and medical specialties. The primary objective of this study is to determine if any factors associated with mentee-mentor partnerships are predictive of publication from two school-sponsored research programs at a single US medical school.
\end{abstract}

Methods: The PubMed-indexed publications of all student-mentor pairings from a summer internship (after year 1 of medical school) or research elective (during year 4 of medical school) at a single institution from 2008 to 2018 were retrospectively reviewed. Student/mentor demographic information was associated with the probability of publication.

Results: A total of 124 students participated in the summer internship with 32 (26\%) achieving publication. The publication was significantly more likely for students that were from highly ranked undergraduate institutions ( $\mathrm{p}=0.04$; likelihood ratio $(\mathrm{LR})=5.788)$, were future Alpha Omega Alpha (AOA) members $(\mathrm{p}=$ $0.03 ; \mathrm{LR}=4.597)$, or worked with a mentor focused on clinical rather than basic science research $(\mathrm{p}=0.02$; $L R=5.662)$. Forty-four students participated in the fourth-year elective with $11(25 \%)$ achieving publication. The publication was more likely if the student worked with a mentor without a Doctor of Medicine $(\mathrm{MD}) /$ Doctor of Osteopathic Medicine (DO) degree $(\mathrm{p}=0.001 ; \mathrm{LR}=7.051)$, with a PhD degree $(\mathrm{p}=0.002 ; \mathrm{LR}=$ $7.820)$, or a mentor with prior publication(s) with prior mentee(s) $(\mathrm{p}=0.03$; LR $=5.368)$.

Conclusion: Only one-quarter of mentor-mentee research pairings resulted in publication, with studentrelated factors more predictive for publication from the internship and mentor-related factors more predictive of publication from the elective. Approaches to promote successful completion of medical student research projects should be considered to yield the greatest value from students' work and strengthen the development of future physician-scientists.

Categories: Medical Education

Keywords: medical student, clinical research, publication, mentor, mentorship

\section{Introduction}

Medical students in the United States often engage in research with faculty mentors, with the potential for both mentee and mentor to derive a variety of benefits from the experience [1-3]. A students' knowledge of research methodology can contribute toward a better understanding of interpreting and critiquing medical literature so that scientific evidence can be applied appropriately to clinical practice [4]. Some students may develop an interest in becoming physician-scientists themselves and improving patient care through discovery. While a research experience has value in and of itself, seeing projects through to publication is an important determinant of its success. Independent of the effect of a publication on changing clinical practice, publications are a critical component of a student becoming a competitive applicant for many specialties in the residency match [5], and research productivity in medical school has been associated with increased research productivity in residency and thus better career placement, especially in cultivating academic physicians [6-11].

Many medical schools offer structured programs to enable students to participate in research during their preclinical and clinical years, but the majority of student-mentor partnerships do not culminate in publication across a variety of institutions and medical specialties [1-2, 11-13]. It is likely that not all student-mentor partnerships and projects have a similar probability of publication from the outset, but little is known about what factors may impact this probability. Having this knowledge could better inform students, mentors, and academic administrators on ways to optimize the value of similar research 
experiences in the future. The primary objective of this study is to determine if any factors related to the student, mentor, or project are predictive of publication in two research programs at a single US medical school.

\section{Materials And Methods \\ Study setting and participants}

This retrospective review included medical students paired individually with a research mentor through (1) a summer research internship or (2) a research elective, at a single institution from 2008 to 2018. This study only included MD candidates and excluded MD/PhD candidates since the latter is on a different track with a greater focus on research in their education. The research internship consists of an optional 10-week paid experience (funding from Dean's office) during the summer following a student's first-year curriculum where mentors were chosen individually by students or assigned based on their specialty of interest. The research elective consists of an optional one-month experience during the fourth year of medical school where mentors were chosen individually by students. Prior to starting both programs, students were expected to submit proposals (under the guidance of their mentor) detailing the hypothesis, objectives, background, methods, and IRB approval information for the project. Upon completion of the program, students were expected to formally present their research results via presentation at an institution-sponsored research event or regional/national meeting.

The primary endpoint of this study was the mentee and mentor collaboration resulting in a publication, whereas a secondary endpoint was to determine the factors associated with multiple publications. Each endpoint was evaluated separately for the summer internship and fourth-year research elective.

Demographics of students and faculty mentors were collected to determine characteristics associated with a higher likelihood of publication. The evaluated independent variables related to the mentors included research focus (basic science or clinical), type of degree, clinical/tenure track level, prior number of publications prior to collaboration, years of institutional employment prior to collaboration, gender (deduced by name and online pictures, including gender discordance from student), prior research mentee(s) through internship or elective, and prior publication with research mentee(s) through internship or elective.

The evaluated independent variables related to the students included gender, number of prior publications, and undergraduate institution ranking (based on US News and World Report 2020 college rankings) [14]. Individual students' grades and standardized test scores were not available for this study; however, to distinguish high-performing medical students, Alpha Omega Alpha (AOA) membership was used as a surrogate, even though students do not actually become AOA members until later in medical school. The primary factor considered for AOA membership at this institution is having grades in the top quartile of one's class during their first two years of medical school. For those students who meet these criteria, secondary factors that are considered include receiving at least two letters of recommendation for academic achievement, attaining a high Step 1 score, taking on leadership positions, and being productive in research.

\section{Data collection}

A list of student and mentor names and titles of their project for each research program were obtained from the directors of each research program. Data related to mentor and mentee demographics were collected via internet search using Google to identify the individual on the website of their current employer, which was typically the primary source of information. This was supplemented and cross-checked with any additional information available on LinkedIn, Google, or prior residency/employment websites. Mentors' information was also frequently available from curriculum vitae posted online. There were minimal discrepancies between the information on the websites that were available. The National Center for Biotechnology Information (NCBI) PubMed database was used to collect publication information. A publication was accredited to a given student-mentor pairing if both were listed as co-authors on the publication and the title of the publication was related to the title of the project in the research program's records. In order to account for surname changes due to marriage, the mentor's publication record was reviewed for both the first name and surname of their female student mentees, and any suspected surname changes were confirmed using similar internet searches as above. If a collaboration resulted in a publication, then the student authorship number, total number of authors, publication journal, and that journal's associated impact factor were also recorded. Publications in "predatory journals," which commonly describe openaccess medical journals that publish articles online with little or no peer review, low academic standards, and little credibility, were not excluded if listed in PubMed.

\section{Statistical analyses}

Associations between the above endpoints and independent variables were evaluated using the Chi-squared, Fisher's exact, and Mann-Whitney U tests, where appropriate. Fisher's exact test was used for comparisons in which $20 \%$ of the cells had expected frequencies less than five; if the contingency tables were large, the Freeman-Halton extension was used [15]. Statistical analysis was carried out using Statistical Package for Social Sciences version 24.0 (SPSS Inc., Chicago, IL). A p-value less than 0.05 was considered statistically significant. 


\section{Cureus}

\section{Results \\ Study participants and characteristics}

After approval by the local institutional review board, data were collected on a total of 336 individual students and their mentors. It included 168 students, with 124 (74\%) participating in the summer internship and 44 (26\%) participating in the research elective as presented in Table 1 . Seven students participated in both programs and were included in the analysis of each. Gender distribution among medical students in both programs was different. Medical school enrollment at this institution is $48 \%$ females, but twice as many male medical students participated in the summer program compared to females $(66.9 \%$ versus $33.1 \%$, respectively); however, the elective year had a similar gender distribution between males and females (52.3\% versus $47.7 \%$, respectively). A large majority of students who participated in the summer research program (83.1\%) had no previous publication record prior to entering the internship program. Across programs, fewer than $25 \%$ of medical students became members of the AOA Medical Honor Society. Students ultimately pursued a wide variety of medical and surgical residency programs after graduating from medical school.

Internship, $\mathbf{n}(\%)$

Elective, $\mathbf{n}(\%)$

Gender

Male

Female

$83(66.9 \%)$

$23(52.3 \%)$

$41(33.1 \%)$

$21(47.7 \%)$

Undergraduate Ranking*

$1-50$

$51-150$

$151-300$

Not Ranked

Unknown

Prior Publications

0

$1-2$

3 or Greater

Alpha Omega Alpha Member

Yes

No

Unknown

Residency Position

Internal Medicine

General Surgery

Anesthesiology

Orthopedics

Ob/Gyn

Family Medicine

Diagnostic Radiology

Pediatrics

Ophthalmology

Plastic Surgery

Emergency Medicine
17 (13.7\%)

$3(6.8 \%)$

$24(19.4 \%)$

$5(11.4 \%)$

$48(38.7 \%)$

$24(54.6 \%)$

$18(14.5 \%)$

$8(18.2 \%)$

$17(13.7 \%)$

$4(9.1 \%)$

$103(83.1 \%)$

$27(61.4 \%)$

18 (14.5\%)

$16(36.4 \%)$

$3(2.4 \%)$

$1(2.3 \%)$

23 (18.6\%)

$11(25.0 \%)$

$100(80.6 \%)$

$32(72.7 \%)$

$1(0.8 \%)$

$1(2.3 \%)$

19 (15.3\%)

$4(9.1 \%)$

11 (8.9\%)

$3(6.8 \%)$

$9(7.3 \%)$

$5(11.4 \%)$

$9(7.3 \%)$

$3(6.8 \%)$

$8(6.5 \%)$

$2(4.6 \%)$

7 (5.6\%)

$2(4.6 \%)$

$5(4.0 \%)$

$2(4.6 \%)$

$4(3.2 \%)$

$4(9.1 \%)$

$4(3.2 \%)$

$3(6.8 \%)$

$3(2.4 \%)$

2 (4.6\%)

$2(1.6 \%)$

$3(6.8 \%)$ 


\section{Cureus}

\begin{tabular}{|c|c|c|}
\hline Pathology & $2(1.6 \%)$ & --- \\
\hline Neurology & $2(1.6 \%)$ & $1(2.3 \%)$ \\
\hline Radiation Oncology & $2(1.6 \%)$ & $1(2.3 \%)$ \\
\hline Otolaryngology & $2(1.6 \%)$ & $1(2.3 \%)$ \\
\hline Dermatology & $1(0.8 \%)$ & $3(6.8 \%)$ \\
\hline Vascular Surgery & $1(0.8 \%)$ & $2(4.6 \%)$ \\
\hline Psychiatry & $1(0.8 \%)$ & $1(2.3 \%)$ \\
\hline Internal Medicine/Pediatrics & $1(0.8 \%)$ & --- \\
\hline Interventional Radiology & $1(0.8 \%)$ & ---- \\
\hline Physical Medicine \& Rehab & $1(0.8 \%)$ & --- \\
\hline Urology & --- & $1(2.3 \%)$ \\
\hline To Be Determined & $23(18.5 \%)$ & ---- \\
\hline Not Applicable & $6(4.8 \%)$ & $\cdots$ \\
\hline
\end{tabular}

TABLE 1: Medical student demographics

* Based on US News and World Report 2020 college rankings.

The distribution and characteristics of mentors included in the study are presented in Table 2. More male mentors were available to medical students in both the internship (81.5\%) and elective program (72.7\%). In the internship program, students selected more tenure track mentors with a $\mathrm{PhD}$ for basic science projects (62.1\%), but this was reversed in the elective program where the majority of mentors were on a clinical track (68.2\%). A total of $72.7 \%$ of mentors in the elective program had not mentored a student in either program previously, and $86.4 \%$ had a mentee with no prior research publications.

\begin{tabular}{|c|c|c|}
\hline & Internship, n (\%) & Elective, $\mathrm{n}(\%)$ \\
\hline \multicolumn{3}{|l|}{ Gender } \\
\hline Male & $101(81.5 \%)$ & $32(72.7 \%)$ \\
\hline Female & $23(18.5 \%)$ & $12(27.3 \%)$ \\
\hline \multicolumn{3}{|l|}{ Degree } \\
\hline MD & $39(31.5 \%)$ & $30(68.2 \%)$ \\
\hline PhD & 77 (62.1\%) & $10(22.7 \%)$ \\
\hline MD/PhD & $8(6.5 \%)$ & $4(9.1 \%)$ \\
\hline \multicolumn{3}{|c|}{ Clinical/Tenure Track Level } \\
\hline Professor & $70(56.5 \%)$ & $17(38.6 \%)$ \\
\hline Associate Professor & $27(21.8 \%)$ & $8(18.2 \%)$ \\
\hline Assistant Professor & $25(20.2 \%)$ & $11(25.0 \%)$ \\
\hline Unknown or N/A & $2(1.6 \%)$ & $8(18.2 \%)$ \\
\hline \multicolumn{3}{|l|}{ Years at Institution } \\
\hline 1 to 5 & $45(36.3 \%)$ & $18(40.9 \%)$ \\
\hline 6 to 10 & $35(28.2 \%)$ & $11(25.0 \%)$ \\
\hline 11 or Greater & $33(26.6 \%)$ & $7(15.9 \%)$ \\
\hline Unknown & $11(8.9 \%)$ & $8(18.2 \%)$ \\
\hline
\end{tabular}




\section{Cureus}

\begin{tabular}{|c|c|c|}
\hline \multicolumn{3}{|l|}{ Research Focus } \\
\hline Basic Science & 72 (58.1\%) & $6(13.6 \%)$ \\
\hline Clinical & $51(41.1 \%)$ & $35(79.6 \%)$ \\
\hline Unknown & $1(0.8 \%)$ & $3(6.8 \%)$ \\
\hline \multicolumn{3}{|c|}{ Prior Mentor Publications } \\
\hline 0 to 10 & $30(24.2 \%)$ & $29(65.9 \%)$ \\
\hline 11 to 30 & $45(36.3 \%)$ & $13(29.6 \%)$ \\
\hline 31 to 50 & $28(22.6 \%)$ & $2(4.6 \%)$ \\
\hline 51 or more & $21(16.9 \%)$ & ---- \\
\hline \multicolumn{3}{|c|}{ Prior Research Mentee } \\
\hline Yes & $63(50.8 \%)$ & $12(27.3 \%)$ \\
\hline No & $61(49.2 \%)$ & $32(72.7 \%)$ \\
\hline \multicolumn{3}{|c|}{ Prior Mentee With Publication } \\
\hline Yes & $44(35.5 \%)$ & $6(13.6 \%)$ \\
\hline No & $80(64.5 \%)$ & $38(86.4 \%)$ \\
\hline \multicolumn{3}{|c|}{ Mentor/Student Gender Concordance } \\
\hline Concordant & $76(61.3 \%)$ & $27(61.4 \%)$ \\
\hline Discordant & $48(38.7 \%)$ & $17(38.6 \%)$ \\
\hline \multicolumn{3}{|c|}{ Gender Concordance Category (Mentor/Student) } \\
\hline Male/Male & $68(54.8 \%)$ & $19(43.2 \%)$ \\
\hline Male/Female & $33(26.6 \%)$ & $13(29.6 \%)$ \\
\hline Female/Male & $15(12.1 \%)$ & $4(9.1 \%)$ \\
\hline Female/Female & $8(6.5 \%)$ & $8(18.2 \%)$ \\
\hline
\end{tabular}

TABLE 2: Mentor demographics

\section{Publication outcomes of medical students in school-sponsored programs}

For the summer internship cohort $(\mathrm{n}=124), 32$ collaborations resulted in publication $(26 \%)$, with a median time until publication of 21 months (IQR, 17-30 months). Seven students (22\%) were the first authors on the publication's byline, 12 students (38\%) were the second authors, and 13 students (41\%) were the third (or higher) authors. The median impact factor of the journal of publication was 1.8 (IQR, 1.4-3.3). Among the students that published, 11 (34\%) had multiple publications with their respective mentor, among which five students (16\%) had three publications with their mentor, and two students (6\%) had four publications with their mentor. At the time of this analysis, 78 of the 124 students (63\%) who participated in the summer internship had at least one publication (with any mentor).

For the research elective cohort $(n=44), 11$ collaborations resulted in publication $(25 \%)$, with a median time until publication of 12 months (IQR, 4-19). Two students (18\%) were the first authors on the publication's byline, three students (27\%) were the second authors, and six students (55\%) were the third (or higher) authors. The median impact factor of the journal of publication was 2.4 (IQR, 1.0-3.9). Among the students that published, eight (73\%) had multiple publications with their respective mentor with five students (45\%) attaining three publications. At the time of this analysis, 30 of the 44 students (68\%) who participated in the research elective had at least one publication (with any mentor).

\section{Factors predictive of student-mentor publication}

Categorical and continuous variables associated with student-mentor publication for each cohort are displayed in Tables 3, 4, respectively. Publication was significantly more likely for students who participated in the internship if they studied at a more highly ranked undergraduate institution $(p=0.04)$, would become 


\section{Cureus}

an AOA member $(p=0.03)$, and worked with a mentor focused on clinical rather than basic science research $(p=0.02)$. Publication was significantly more likely for students who participated in the elective if they worked with a mentor without a Doctor of Medicine (MD)/Doctor of Osteopathic Medicine (DO) degree $(\mathrm{p}=$ $0.001)$, with a $\mathrm{PhD}$ degree $(\mathrm{p}=0.002)$, or who had publication(s) with prior mentee(s) $(\mathrm{p}=0.03)$.

\begin{tabular}{|c|c|c|c|c|c|c|}
\hline & Internship & & & Elective & & \\
\hline & $\begin{array}{l}\text { Publication } \\
\text { (\%) }\end{array}$ & $\begin{array}{l}\text { No Publication } \\
\text { (\%) }\end{array}$ & $\begin{array}{l}\text { p- } \\
\text { value }\end{array}$ & $\begin{array}{l}\text { Publication } \\
\text { (\%) }\end{array}$ & $\begin{array}{l}\text { No Publication } \\
\text { (\%) }\end{array}$ & p-value \\
\hline \multicolumn{7}{|l|}{ Student Gender } \\
\hline Male & $21(66 \%)$ & $62(6 / \%)$ & 0.86 & $8(/ 3 \%)$ & $15(46 \%)$ & 0.12 \\
\hline Female & $11(34 \%)$ & $30(33 \%)$ & & $3(27 \%)$ & $18(55 \%)$ & \\
\hline \multicolumn{7}{|c|}{ Student Undergraduate IIer } \\
\hline $1(\# 1-50)$ & $8(36 \%)$ & $9(13 \%)$ & 0.04 & $2(25 \%)$ & $1(4 \%)$ & 0.23 \\
\hline 2 (\#51-150) & $6(27 \%)$ & $18(2 / \%)$ & & $1(13 \%)$ & $4(1 / \%)$ & \\
\hline $3(\# 151-300)$ & $8(36 \%)$ & $40(60 \%)$ & & $5(63 \%)$ & $19(/ 9 \%)$ & \\
\hline \multicolumn{7}{|c|}{ Student Prior Publications } \\
\hline 0 & $27(84 \%)$ & $76(83 \%)$ & 0.23 & $6(55 \%)$ & $21(64 \%)$ & 0.79 \\
\hline $1-2$ & $4(13 \%)$ & $14(15 \%)$ & & $5(46 \%)$ & $11(33 \%)$ & \\
\hline 3 or More & $3(3 \%)$ & $2(2 \%)$ & & $0(0 \%)$ & $1(3 \%)$ & \\
\hline \multicolumn{7}{|l|}{ Student AOA Member } \\
\hline Yes & $10(32 \%)$ & $13(14 \%)$ & 0.03 & $4(36 \%)$ & $7(22 \%)$ & 0.28 \\
\hline No & $21(67 \%)$ & $79(86 \%)$ & & $7(64 \%)$ & $25(78 \%)$ & \\
\hline \multicolumn{7}{|l|}{ Mentor Gender } \\
\hline Male & $28(88 \%)$ & $73(19 \%)$ & 0.31 & $9(82 \%)$ & $23(10 \%)$ & 0.10 \\
\hline Female & $4(12 \%)$ & $19(21 \%)$ & & $2(18 \%)$ & $10(30 \%)$ & \\
\hline \multicolumn{7}{|c|}{ Mentor With MD/DO Degree } \\
\hline Yes & $12(38 \%)$ & $35(38 \%)$ & 0.96 & $4(36 \%)$ & $30(91 \%)$ & 0.001 \\
\hline No & $20(62 \%)$ & $57(62 \%)$ & & $7(64 \%)$ & $3(9 \%)$ & \\
\hline \multicolumn{7}{|c|}{ Mentor With a PhD Degree } \\
\hline Yes & $22(69 \%)$ & $63(69 \%)$ & 0.98 & $8(73 \%)$ & $6(18 \%)$ & 0.002 \\
\hline No & $10(31 \%)$ & $29(31 \%)$ & & $3(27 \%)$ & $27(82 \%)$ & \\
\hline \multicolumn{7}{|c|}{ Mentor Clinical/Tenure Level } \\
\hline Assistant Professor & $4(13 \%)$ & $21(23 \%)$ & 0.39 & $2(22 \%)$ & $9(33 \%)$ & 0.88 \\
\hline Associate Professor & $7(22 \%)$ & $20(22 \%)$ & & $2(22 \%)$ & $6(22 \%)$ & \\
\hline Professor & $21(66 \%)$ & $49(54 \%)$ & & $5(56 \%)$ & $12(44 \%)$ & \\
\hline \multicolumn{7}{|c|}{ Mentor Research Focus } \\
\hline Basic Science & $13(41 \%)$ & $59(65 \%)$ & 0.02 & $1(9 \%)$ & $5(17 \%)$ & 0.48 \\
\hline Clinical & $19(59 \%)$ & $32(35 \%)$ & & $10(91 \%)$ & $25(83 \%)$ & \\
\hline \multicolumn{7}{|c|}{ Mentor Had Prior Mentee(s) } \\
\hline Yes & $19(59 \%)$ & $44(48 \%)$ & 0.26 & $5(46 \%)$ & $7(21 \%)$ & 0.12 \\
\hline No & $13(41 \%)$ & $48(52 \%)$ & & $6(55 \%)$ & $26(79 \%)$ & \\
\hline Mentor Had Prior Pu & & & & & & \\
\hline
\end{tabular}




\section{Cureus}

\begin{tabular}{|c|c|c|c|c|c|c|}
\hline \multicolumn{7}{|c|}{ Mentee(s) } \\
\hline Yes & $14(44 \%)$ & $30(33 \%)$ & 0.26 & $4(36 \%)$ & $2(6 \%)$ & 0.03 \\
\hline No & $18(56 \%)$ & $62(67 \%)$ & & $7(64 \%)$ & $31(94 \%)$ & \\
\hline \multicolumn{7}{|c|}{ Mentor/Student Gender Concordance } \\
\hline Yes & $17(53 \%)$ & $59(64 \%)$ & 0.27 & $8(73 \%)$ & $19(58 \%)$ & 0.30 \\
\hline No & $15(47 \%)$ & $33(36 \%)$ & & $3(27 \%)$ & $14(42 \%)$ & \\
\hline
\end{tabular}

TABLE 3: Associations between categorical independent variables and the probability of a mentor-mentee relationship resulting in publication for students who participated in the internship or elective programs

AOA, Alpha Omega Alpha.

\begin{tabular}{|l|l|l|l|l|l|}
\hline & Internship & & Elective & \\
\hline & Publication (IQR) & No Publication (IQR) & p-value & Publication (IQR) & No Publication (IQR) \\
\hline
\end{tabular}

TABLE 4: Associations between continuous independent variables and the probability of a mentor-mentee relationship resulting in publication for students who participated in the internship or elective programs

IQR, Interquartile range.

Categorical and continuous variables associated with multiple mentor-mentee publications for both internship and elective cohorts are displayed in Tables 5, 6, respectively. Multiple publications were significantly more likely for students who participated in the internship if they worked with a mentor focused on clinical rather than basic science research $(p=0.050)$. Multiple publications were significantly more likely for students who participated in the elective if the student had published previously $(\mathrm{p}=0.045)$.

\begin{tabular}{|c|c|c|c|c|c|c|}
\hline & Internship & & & Elective & & \\
\hline & $\begin{array}{l}\text { Multiple } \\
\text { Publications (\%) }\end{array}$ & $\begin{array}{l}\text { No Multiple } \\
\text { Publication (\%) }\end{array}$ & $\begin{array}{l}\mathrm{p}- \\
\text { value }\end{array}$ & $\begin{array}{l}\text { Multiple } \\
\text { Publications (\%) }\end{array}$ & $\begin{array}{l}\text { No Multiple } \\
\text { Publication (\%) }\end{array}$ & $\begin{array}{l}\mathrm{p} \text { - } \\
\text { value }\end{array}$ \\
\hline \multicolumn{7}{|c|}{ Student Gender } \\
\hline Male & $8(73 \%)$ & $75(66 \%)$ & 1.00 & $6(75 \%)$ & $17(47 \%)$ & 0.15 \\
\hline Female & $3(27 \%)$ & $38(34 \%)$ & & $2(25 \%)$ & $19(53 \%)$ & \\
\hline \multicolumn{7}{|c|}{ Student Undergraduate Tier } \\
\hline $1(\# 1-50)$ & $3(38 \%)$ & $14(17 \%)$ & 0.37 & $2(40 \%)$ & $1(4 \%)$ & 0.07 \\
\hline 2 (\#51-150) & $2(25 \%)$ & $22(27 \%)$ & & $0(0 \%)$ & $5(19 \%)$ & \\
\hline 3 (\#151-300) & $3(38 \%)$ & $45(56 \%)$ & & $3(60 \%)$ & $21(78 \%)$ & \\
\hline \multicolumn{7}{|c|}{ Student Prior Publications } \\
\hline 0 & $10(91 \%)$ & $93(82 \%)$ & 0.14 & $2(25 \%)$ & $25(69 \%)$ & 0.045 \\
\hline $1-2$ & $0(0 \%)$ & $18(16 \%)$ & & $6(75 \%)$ & $10(28 \%)$ & \\
\hline 3 or More & $1(9 \%)$ & $2(2 \%)$ & & $0(0 \%)$ & $1(3 \%)$ & \\
\hline
\end{tabular}




\section{Cureus}

Student AOA Member

Yes

No

Mentor Gender

Male

Female

Mentor With MD/DO Degree

Yes

No

Mentor With PhD Degree

Yes

No

Mentor Clinical/Tenure Level

Assistant Professor

Associate Professor

Professor

Mentor Research Focus

Basic Science

Clinical

Mentor Had Prior Mentee(s)

Yes

No

Mentor Had Prior Publication(s)

With Mentee(s)

Yes

No

Mentor/Student Gender

Concordance

Yes

No
$3(27 \%)$

$8(73 \%)$

$9(82 \%)$

$2(18 \%)$

$5(46 \%)$

$6(54 \%)$

$8(73 \%)$

$3(27 \%)$

$2(18 \%)$

$2(18 \%)$

7 (64\%)

$3(27 \%)$

$8(73 \%)$

$69(62 \%)$

$43(38 \%)$

$8(73 \%)$

$3(27 \%)$

55 (49\%)

$58(51 \%)$

$6(55 \%)$

$38(34 \%)$

75 (66\%)

$5(45 \%)$

$6(55 \%)$

$5(46 \%)$
$0.43 \quad 3(38 \%)$

$8(23 \%)$

27 (77\%)

$5(63 \%)$

$1.007(88 \%)$

25 (69\%)

$1(12 \%)$

$11(31 \%)$

$0.75 \quad 4(50 \%)$

$30(83 \%)$

$4(50 \%)$

$6(17 \%)$

$1.00 \quad 5(63 \%)$

$3(38 \%)$

$9(25 \%)$

27 (75\%)

$1.00 \quad 0(0 \%)$

$11(37 \%)$

0.13

$1(17 \%)$

7 (23\%)

$5(83 \%)$

$12(40 \%)$

$0.050 \quad 0(0 \%)$

$6(18 \%)$

0.25

$8(100 \%)$

27 (82\%)

$9(25 \%)$

0.38

$5(63 \%)$

27 (75\%)

$0.203(38 \%)$

$3(8 \%)$

0.06

$5(63 \%)$

$33(92 \%)$

$22(61 \%)$

0.64

TABLE 5: Associations between categorical independent variables and the probability of a mentor-mentee relationship resulting in multiple publications for students participating in the internship or elective programs

AOA, Alpha Omega Alpha. 


\section{Cureus}

\begin{tabular}{|c|c|c|c|c|c|c|}
\hline & Internship & & & Elective & & \\
\hline & $\begin{array}{l}\text { Multiple Publication } \\
\text { (IQR) }\end{array}$ & $\begin{array}{l}\text { No Multiple Publication } \\
\text { (IQR) }\end{array}$ & $\begin{array}{l}\mathrm{p} \text { - } \\
\text { value }\end{array}$ & $\begin{array}{l}\text { Multiple Publication } \\
\text { (IQR) }\end{array}$ & $\begin{array}{l}\text { No Multiple Publication } \\
\text { (IQR) }\end{array}$ & $\begin{array}{l}\mathrm{p}- \\
\text { value }\end{array}$ \\
\hline Mentor Years at Institution & $6(5-10)$ & $7(4-12)$ & 0.63 & $9(5-13)$ & $5(4-8)$ & 0.16 \\
\hline Prior Mentor Publications & $16(29-57)$ & $22(11-42)$ & 0.28 & $10(5-19)$ & $4(2-17)$ & 0.19 \\
\hline $\begin{array}{l}\text { Mentor Publications Within } 3 \\
\text { Years }\end{array}$ & $9(5-16)$ & $11(5-15)$ & 0.90 & $6(3-8)$ & $3(0-7)$ & 0.09 \\
\hline
\end{tabular}

TABLE 6: Associations between continuous independent variables and the probability of a mentor-mentee relationship resulting in multiple publications for students participating in the internship or elective programs

$I Q R$, Interquartile range

\section{Discussion}

Research is a critical component of medical education, both in the context of practicing evidence-based medicine and for the purpose of scholarship and discovery. As such, opportunities for students to pursue mentored research projects are common at many medical schools $[1,12,13]$ as well as through many national specialty societies hoping to promote greater academic interest in their field $[11,16]$. As in prior studies evaluating general research programs for all medical students regardless of their specialty of interest (or the specialty of their mentor), we found that approximately one in four mentor-mentee research pairings resulted in a manuscript publication in a PubMed-indexed medical journal, and two-thirds of participants published an article on any topic in their subsequent careers. This is comparable to what has been reported for a similar program at other institutions $[2,11,17]$ and suggests that participation in any organized research program is associated with the pursuit of future research $[16,18]$. Our findings are unique in reporting outcomes of two different medical student research experiences at a single institution and in describing factors associated with publication.

Interestingly, student-related factors were most predictive of publication from summer internship projects, and mentor-related factors were most predictive of publication of fourth-year elective projects. It is perhaps not surprising that early in medical school, students who attended a more highly ranked college, or who have higher grades (as suggested by future AOA membership), would also be more successful in their research projects [19]. Attending a more highly ranked college may be associated with prior opportunities and exposure to research leading to a better understanding of how to perform in a research setting during medical school. Or alternatively, since most publications did not occur for many months afterward the research period, a student's ability to merit co-authorship may have more to do with sustained engagement in the project even while balancing it with their medical school course work before and after the research period.

The type of project pursued is another important factor, with clinical projects typically being less timeconsuming and perhaps easier to sustain during the school year than basic science laboratory work. Furthermore, although authorship criteria are relatively standardized across medical and biomedical journals, mentors' views on what merits authorship may vary. For instance, it is possible that basic scientists may be more rigorous than their clinical counterparts in their authorship requirements since the former is perhaps more used to engaging MS or $\mathrm{PhD}$ degree candidates for whom publishing a manuscript is a component of earning their degree. Notably, predictors of a more prestigious first-author publication were also not assessed in this study due to the relatively small number of them and because the faculty mentors' criteria to make a student first author are likely to vary substantially from one project to another based on the type of project, number and type of other people involved in it, and the relative contributions of each person. Unexpectedly, prior publications from the student or mentor did not impact the probability of publication from the pairing for the internship program.

The factors associated with publication in the fourth-year student elective program differed, likely related to the type of student who pursues this very different experience. Elective projects were published more quickly than internship projects and eight out of 11 students with publications in this cohort had multiple publications with their elective mentor. Both of these findings suggest students may have had pre-existing projects with mentors and completed them during the elective period. On the other hand, new elective projects with a clinical mentor, who a student perhaps met during the third- and fourth-year clinical rotations rather than selected specifically for research purposes, were less likely to result in publication. This may account for the fact that publication was more common with mentors with a PhD than with an MD or DO degree in the elective program. For instance, five physicians who served as elective research mentors 
had zero publications, including one mentor who worked with four students, and it is not surprising that none of these pairings resulted in a student publication. Unfortunately, some students may participate in the fourth-year elective for purposes other than research, like having free time for residency interviews. In general, we believe that if elective programs like this are going to be meaningful for students, there needs to be a more structured program with goals and expectations as well as significant vetting of experienced mentors who have a track record of publications, particularly with students they have worked with in the past. These types of programs have been implemented at some medical schools [1,13]. Other support structures like a mentor development program may also be worthwhile to help generate a larger pool of high-quality mentors to best serve students' needs. Otherwise, students would be better served on any clinical rotation that the research elective took the place of. Clearly, clinical mentors and clinical projects can work well for students as shown in the internship data, and perhaps more clinicians need to promote their availability as a mentor during the summer internship when more basic science projects were pursued, despite more clinical projects being published.

There are several limitations to this study. Most importantly, it was conducted at a single institution, which is not among the top 40 US medical schools with the highest National Institute of Health research funding. Factors associated with publication for these types of medical student research programs may differ at more robust research institutions [20]. Furthermore, being a public medical school, the majority of students were from the same state or received an undergraduate degree at this state university and may have more homogeneous backgrounds than at some private medical schools, despite the wide variety of specialties that the students ultimately pursued. Also, PubMed was the only database searched, and it is possible that medical students' articles were published in non-indexed journals or potentially using a different name.

Likewise, online searches to obtain demographic information has limitations for certain variables. For instance, while we believe that most surname changes for female students were captured (particularly related to publications with their mentor), some may not have been. Also, while the variables clinical/tenure track level and years of institutional employment provide some information on how advanced each faculty member was in their academic career, we could not determine the actual length of each faculty members' academic career due to inability to obtain reliable prior employment history. There are also potentially other variables related to the mentor-mentee relationship and the extent of students' contribution to the research that may have influenced publication and may have been better assessed using qualitative approaches that were not feasible in this retrospective study. Finally, there were only fewer students who participated in the research elective compared to the summer internship, which limits the power of our analysis for the elective cohort.

\section{Conclusions}

The findings from this study may assist medical student administrators in looking critically at the research programs that they offer to their students and provide useful information to students and mentors as they select a research collaboration. Publication after the summer internship was more likely for students that were from highly ranked undergraduate institutions, were future AOA members, or worked with a mentor focused on clinical rather than basic science research. Publication after the research elective was more likely if the student worked with a mentor without an MD/DO degree, with a PhD degree, or a mentor with prior publication(s) with prior mentee(s).

\section{Additional Information \\ Disclosures}

Human subjects: Consent was obtained or waived by all participants in this study. Animal subjects: All authors have confirmed that this study did not involve animal subjects or tissue. Conflicts of interest: In compliance with the ICMJE uniform disclosure form, all authors declare the following: Payment/services info: All authors have declared that no financial support was received from any organization for the submitted work. Financial relationships: All authors have declared that they have no financial relationships at present or within the previous three years with any organizations that might have an interest in the submitted work. Other relationships: All authors have declared that there are no other relationships or activities that could appear to have influenced the submitted work.

\section{References}

1. Laskowitz DT, Drucker RP, Parsonnet J, Cross PC, Gesundheit N: Engaging students in dedicated research and scholarship during medical school: the long-term experiences at Duke and Stanford. Acad Med. 2010, 85:419-28. 10.1097/ACM.0b013e3181ccc77a

2. Zier K, Friedman E, Smith L: Supportive programs increase medical students' research interest and productivity. J Investig Med. 2006, 54:201-7. 10.2310/6650.2006.05013

3. Jacobs CD, Cross PC: The value of medical student research: the experience at Stanford University School of Medicine. Med Educ. 1995, 29:342-6. 10.1111/j.1365-2923.1995.tb00023.x

4. Liaison Committee on Medical Education. Functions and structure of a medical school: Standards for Accreditation of Medical Education Programs leading to the MD degree. (2008). Accessed: August 2, 2021: https://med.fsu.edu/sites/default/files/userFiles/file/FacultyDevelopment_Functions_and_Structure_of_a_Medical_School..

5. Main residency match data and reports . (2020). Accessed: August 2, 2021: https://www.nrmp.org/main- 
residency-match-data/.

6. Gupta R, Norris ML, Writer H: Preresidency publication record and its association with publishing during paediatric residency. Paediatr Child Health. 2016, 21:187-90. 10.1093/pch/21.4.187

7. Grimm LJ, Shapiro LM, Singhapricha T, Mazurowski MA, Desser TS, Maxfield CM: Predictors of an academic career on radiology residency applications. Acad Radiol. 2014, 21:685-90. 10.1016/j.acra.2013.10.019

8. Gutovich JM, Den RB, Werner-Wasik M, Dicker AP, Lawrence YR: Predictors of radiation oncology resident research productivity. J Am Coll Radiol. 2013, 10:185-9. 10.1016/j.jacr.2012.06.036

9. Kohlert S, Zuccaro L, McLean L, Macdonald K: Does medical school research productivity predict a resident's research productivity during residency?. J Otolaryngol Head Neck Surg. 2017, 46:34. 10.1186/s40463-0170202-6

10. Rezek I, McDonald RJ, Kallmes DF: Pre-residency publication rate strongly predicts future academic radiology potential. Acad Radiol. 2012, 19:632-4. 10.1016/j.acra.2011.11.017

11. Toledo P, McLean S, Duce L, Wong CA, Schubert A, Ward DS: Evaluation of the Foundation for Anesthesia Education and Research Medical Student Anesthesia Research Fellowship Program participants' scholarly activity and career choices. Anesthesiology. 2016, 124:1168-73. 10.1097/ALN.0000000000001068

12. Cain L, Kramer G, Ferguson M: The Medical Student Summer Research Program at the University of Texas Medical Branch at Galveston: building research foundations. Med Educ Online. 2019, 24:1581523. 10.1080/10872981.2019.1581523

13. Boninger M, Troen $\mathrm{P}$, Green E, et al.: Implementation of a longitudinal mentored scholarly project: an approach at two medical schools. Acad Med. 2010, 85:429-37. 10.1097/ACM.0b013e3181ccc96f

14. Best National University rankings. (2020). Accessed: August 2, 2021: https://www.usnews.com/bestcolleges/rankings/national-universities.

15. Bewick V, Cheek L, Ball J: Statistics review 8: qualitative data - tests of association . Crit Care. 2004, 8:46-53. 10.1186/cc2428

16. Smith WH, Rogers JG, Hansen TN, Smith CV: Early career development in academic pediatrics of participants in the APS-SPR Medical Student Research Program. Pediatr Res. 2009, 65:474-7. 10.1203/PDR.0b013e3181975f85

17. Dorrance KA, Denton GD, Proemba J, La Rochelle J, Nasir J, Argyros G, Durning SJ: An internal medicine interest group research program can improve scholarly productivity of medical students and foster mentoring relationships with internists. Teach Learn Med. 2008, 20:163-7. 10.1080/10401330801991857

18. Solomon SS, Tom SC, Pichert J, Wasserman D, Powers AC: Impact of medical student research in the development of physician-scientists. J Investig Med. 2003, 51:149-56. 10.1136/jim-51-03-17

19. Chusid MJ, Havens PL, Coleman CN: Alpha omega alpha election and medical school thesis publication: relationship to subsequent publication rate over a twenty-year period. Yale J Biol Med. 1993, 66:67-73.

20. Wadhwa H, Shah SS, Shan J, et al.: The neurosurgery applicant's "arms race": analysis of medical student publication in the Neurosurgery Residency Match. J Neurosurg. 2019, 1-9. 10.3171/2019.8.JNS191256 